Check for updates

Cite this: RSC Adv., 2017, 7, 54326

Received 15th October 2017

Accepted 22nd November 2017

DOI: $10.1039 / c 7 r a 11370 f$

rsc.li/rsc-advances

\section{Large-scale synthesis of polyhedral Ag nanoparticles for printed electronics}

\author{
Shlomi Polani, ${ }^{a}$ Semyon Melamed, ${ }^{\mathrm{b}}$ Luba Burlaka, ${ }^{a}$ Fernando De La Vegab \\ and David Zitoun (iD *a
}

Printed electronics mainly use ink that contains silver with a high weight fraction to print conductive patterns. The synthesis of polyhedral Ag nanoparticles has been previously reported for lab-scale batches with a low weight fraction. The clean synthesis of large batches with homogeneous size and shape and high-volume fraction and conductivity is still challenging. Here, we report an original pathway to yield large batches of high weight fraction (typically $60 \mathrm{~g}$ of $50 \mathrm{wt} \%$ ink). The synthetic route goes through the formation of $\mathrm{Ag}_{2} \mathrm{O}$, which is then reduced by $\mathrm{H}_{2} \mathrm{O}_{2}$ in the presence of a stabilizing polymer. The mechanism is discussed in view of the phase and composition analysis of the samples during the reaction. After printing lines of Ag NPs, the electrical properties of the Ag lines were measured, and the results are discussed along with the microstructure. The electrical resistivity reached values as low as 6.6 times the bulk value after mild annealing at $200{ }^{\circ} \mathrm{C}$ for 45 minutes.

\section{Introduction}

A variety of methods have been reported for the synthesis of silver polyhedral nanoparticles (NPs) with a range of different shapes and controllable sizes, including cubes, rods, wires, and octahedra. ${ }^{1-4}$ To use silver polyhedral NPs in applications such as printed electronics, ${ }^{\mathbf{5 , 6}}$ the synthesis must yield large batches with a high volume fraction (20-60\%) of homogeneously distributed (size and shape) Ag polyhedral NPs, even if polydispersity could also be beneficial to reach a high metallic ratio in the printed features. Nevertheless, many protocols found in the literature are based on very low concentrations and small volumes of reagents, and the scaleup is often not straightforward. As a consequence, most of the NPs described in the literature are not commercially available due to the lack of large batches (mass per batch) or their excessive cost.

At the research lab-scale, various reducing agents were used to form metallic silver $\left(\mathrm{Ag}^{0}\right)$ by the reduction of silver ions $\left(\mathrm{Ag}^{+}\right)$in aqueous or non-aqueous solutions, ${ }^{7,8}$ followed by stabilization and growth, including sodium borohydride $\left(\mathrm{NaBH}_{4}\right),{ }^{9}$ ascorbic acid, ${ }^{10}$ tannic acid, ${ }^{11}$ and polyols. ${ }^{12,13}$ Microwave-assisted synthetic methods were found to be efficient, environmentally friendly, and economically viable. ${ }^{\mathbf{1 4}}$ In the polyol synthesis, diols such as ethylene glycol reduce $\mathrm{Ag}^{+}$to metallic silver in the presence of poly(vinyl pyrrolidone) (PVP), which acts not only as a stabilizer, but

${ }^{a}$ Department of Chemistry, Bar Ilan Institute of Nanotechnology and Advanced Materials (BINA), Ramat Gan 52900, Israel. E-mail: David.Zitoun@biu.ac.il

${ }^{b}$ PV Nano Cell Ltd., 8 Hamasger st. P.O. Box 236, Migdal Ha'Emek, 2310102, Israel also as a shaping agent. Face-centered cubic (FCC) silver exhibits different crystallographic planes, and the selective interaction of PVP with the different planes can largely reduce or enhance the growth rate along the (100) direction. The PVP molar ratio (in terms of repeating unit) relative to the silver precursor has an important role in determining the morphology and size of the NPs. ${ }^{\mathbf{9 1 3 - 1 5}}$

A rather less known and very original synthetic route to produce metallic silver involves a particle-mediated pathway in which silver(I) oxide $\left(\mathrm{Ag}_{2} \mathrm{O}\right)$ usually serves as a sacrificial template, and $\mathrm{NaBH}_{4}$ or $\mathrm{H}_{2} \mathrm{O}_{2}$ act as the reducing agent. First, $\mathrm{Ag}^{+}$is converted to silver(I) oxide by significantly raising the $\mathrm{pH}$ of the medium. The resultant oxide phase is then reduced to metallic silver. The use of $\mathrm{NaOH}$ to produce a solid $\mathrm{Ag}_{2} \mathrm{O}$ phase, $\mathrm{Ag}_{2} \mathrm{O}_{(\mathrm{s})}$, is known in the literature; silver ions in the presence of $\mathrm{OH}^{-}$ions form $\mathrm{AgOH}_{(\mathrm{aq})}$, which quickly decomposes and precipitates to form the desired $\mathrm{Ag}_{2} \mathrm{O}_{(\mathrm{s})}:{ }^{\mathbf{1 6 - 1 8}}$

$$
2 \mathrm{Ag}_{(\mathrm{aq})}{ }^{+}+2 \mathrm{OH}_{(\mathrm{aq})}{ }^{-} \rightarrow \mathrm{Ag}_{2} \mathrm{O}_{(\mathrm{s})}+\mathrm{H}_{2} \mathrm{O}_{(\mathrm{l})}
$$

Silver(I) oxide reacts with hydrogen peroxide to form metallic silver. The reaction takes place on the surface of the silver oxide structure: ${ }^{19}$

$$
\mathrm{Ag}_{2} \mathrm{O}_{(\mathrm{s})}+\mathrm{H}_{2} \mathrm{O}_{2(\mathrm{aq})} \rightarrow 2 \mathrm{Ag}_{(\mathrm{s})}+\mathrm{H}_{2} \mathrm{O}_{(\mathrm{l})}+\mathrm{O}_{2(\mathrm{~g})}
$$

$\mathrm{NaBH}_{4}$ can also reduce silver oxide to metallic silver. ${ }^{20,21}$ The final product morphology and size depend strongly on the crystallographic nature of the sacrificial template. ${ }^{17}$ 
Here, we leverage the synthesis of $\mathrm{Ag}$ from $\mathrm{Ag}_{2} \mathrm{O}$ to produce inks of polyhedral silver NPs in large batches $(60 \mathrm{~g})$ of $50 \%$ weight fraction through an aqueous procedure, more sustainable and green than the common polyol synthesis. The mechanism was studied by the phase analysis of the products at different quenching times by powder X-ray diffraction, transmission electron microscopy, and scanning electron microscopy. The silver ink displays a very high conductivity only 6.6 times lower than the bulk value after a mild annealing.

\section{Results and discussion}

\section{Synthesis and structural characterization}

The synthesis yielded large batches of high volume fraction Ag polyhedral NPs. The particle size distribution (PSD) was centered on $64 \mathrm{~nm}$ with a standard deviation of $20 \mathrm{~nm}$, as obtained from averaging each particle to a sphere and counting 100 nanoparticles randomly from the SEM images. This result is in good agreement with dynamic light scattering analysis (not
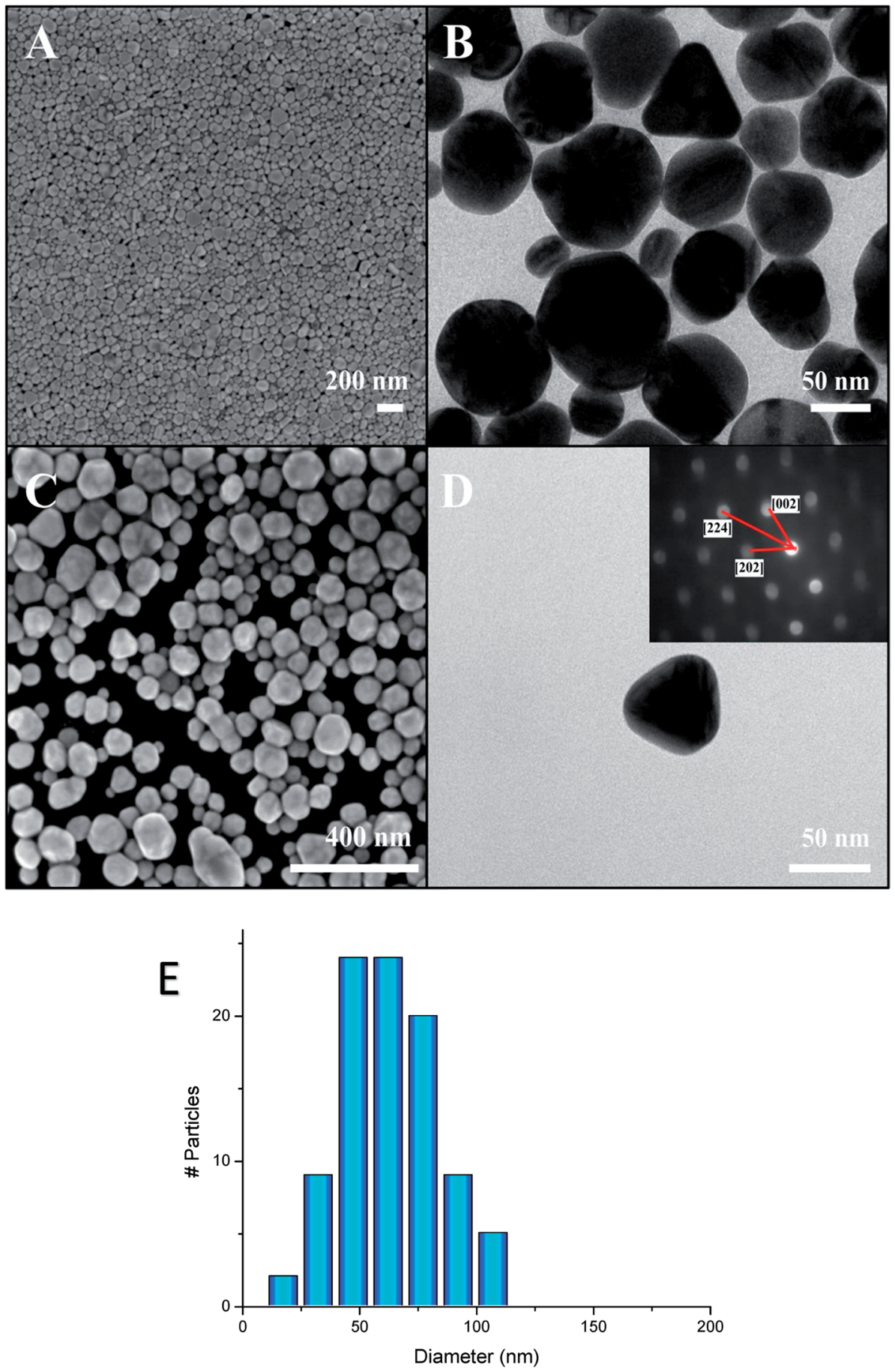

Fig. 1 Scanning electron microscopy (SEM) image of Ag polyhedral NPs (A \& C); transmission electron microscopy (TEM) image of an ensemble (B) and a single Ag NPs with the electron diffraction pattern in inset (D); size histogram of the NPs from SEM images (E). 


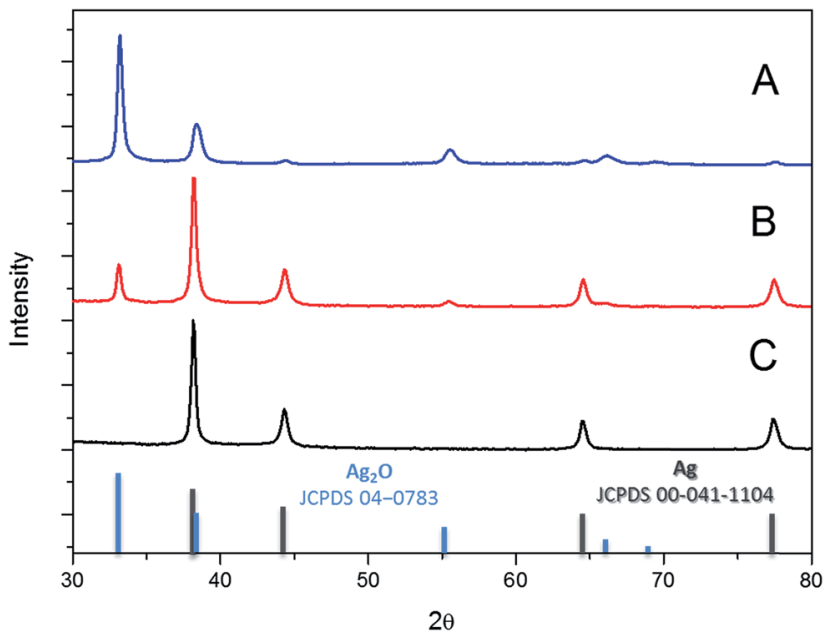

Fig. 2 Powder $X$-ray diffractograms (PXRD) of the reaction intermediates ( $\mathrm{A}$ and $\mathrm{B}$ ) and the product of the completed reaction (C).

reported here). The reaction was complete based on the utilization of $\mathrm{AgNO}_{3}$, and the batches comprised exclusively of faceted polyhedral Ag NPs (Fig. 1A-D). The electron diffraction pattern of a single particle reveals its single crystalline nature with a face-centered cubic (FCC) pattern (inset, Fig. 1D).

The X-ray diffractogram of the dried Ag polyhedral NPs shows the exclusive formation of FCC silver (JCPDS 04-0783, Fig. 2C). The reaction mechanism was investigated by the addition of a sub-stoichiometric amount of the reducing agent $\mathrm{H}_{2} \mathrm{O}_{2}$ (Fig. $2 \mathrm{~A}$ and B). In the first experiment, only $10 \%$ of the typical amount of $\mathrm{H}_{2} \mathrm{O}_{2}$ was added to the colloidal dispersion (Fig. 2A), and the XRD showed a major phase of $\mathrm{Ag}_{2} \mathrm{O}$ (JCPDS 00041-1104) with a minor phase of FCC Ag. When the amount of hydrogen peroxide was increased up to $50 \%$, the ratio between the $\mathrm{Ag}$ and $\mathrm{Ag}_{2} \mathrm{O}$ phases increased (Fig. 2B) until the completion of the reaction with the presence of a single FCC Ag phase (Fig. 2C).

A SEM analysis was performed on the two samples. In the first case ( $10 \%$ hydrogen peroxide) the SEM shows large micronscale rectangular-shaped particles, which could not be found in the typical synthesis (Fig. 3A). Apart from these large particles, the sample consists of a film of NPS with a size below $100 \mathrm{~nm}$, corresponding to the typical size of the Ag polyhedral NPs (Fig. 3A, area 1). Energy dispersive X-ray spectroscopy (EDS) was performed on several areas of the film. In area 1 ,

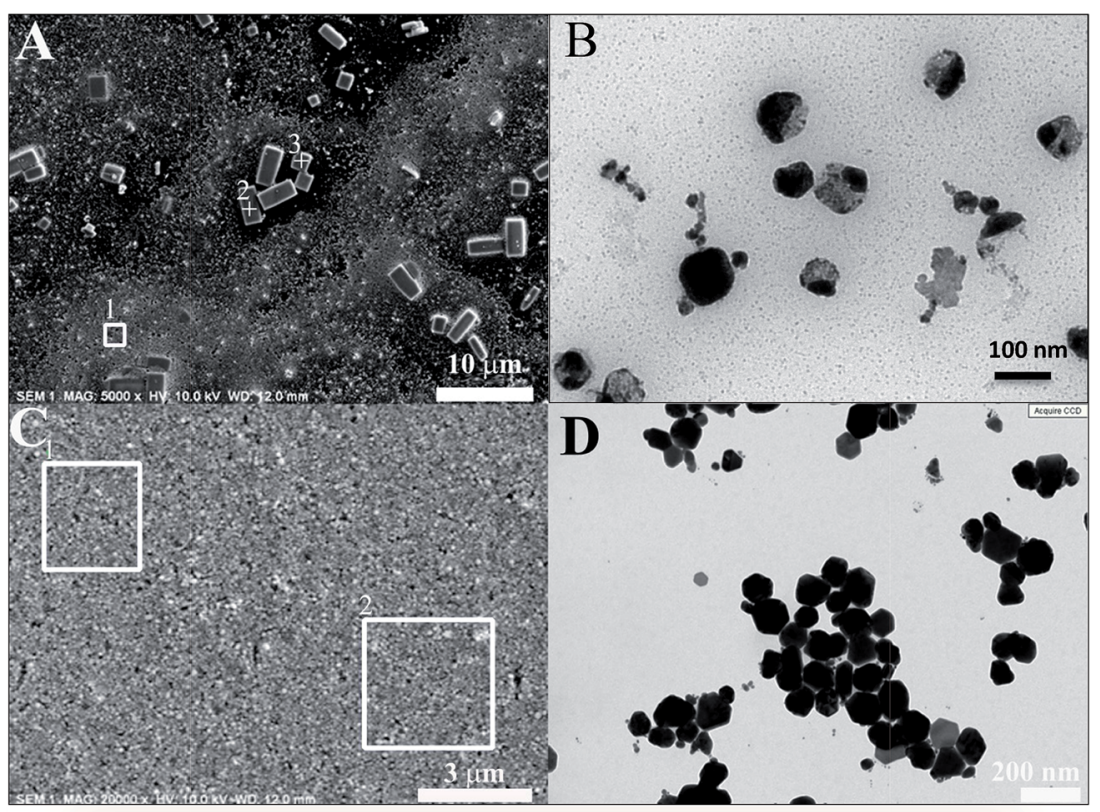

$\mathrm{E}$

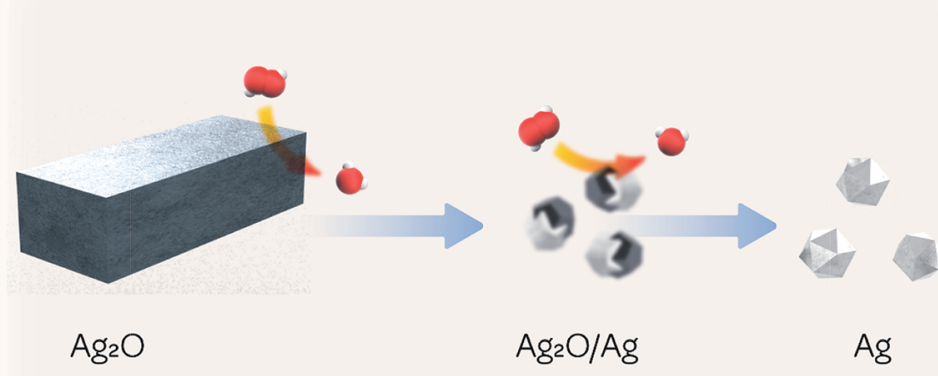

Fig. 3 SEM \& TEM micrographs of the reaction intermediate (A \& B respectively) and after completion of the reaction (C \& $D$ respectively). The white squares and dots on the SEM images correspond to the acquisition of EDS. Schema of the reaction mechanism (E). 
a representative area of the Ag NPs film, the only element found was $\mathrm{Ag}$, with a level of $\mathrm{C}$ and $\mathrm{O}$ below the detection limit. On the other hand, the EDS spectra from the rectangular shape microparticles, spots $2 \& 3$, agree quantitatively with an atomic $\mathrm{Ag} / \mathrm{O}$ ratio of $2: 1$, corresponding to the $\mathrm{Ag}_{2} \mathrm{O}$ oxide observed by XRD (Fig. 3A). A low level of potassium was detected in those crystals, which could arise from the presence of a minute amount of KOH. TEM also shows a bimodal distribution of large $\mathrm{Ag}_{2} \mathrm{O}$ particles and $\mathrm{Ag}$ NPs (Fig. 3B). The largest rectangular-shaped microparticles are excluded from the TEM grid. Interestingly, the mid-size particles show a Z-contrast. This $\mathrm{Z}$-contrast could be due to the chemical composition (Ag or $\mathrm{Ag}_{2} \mathrm{O}$, Fig. 3B), meaning that the reaction goes through an intermediate step with biphasic $\mathrm{Ag} / \mathrm{Ag}_{2} \mathrm{O}$ NPs. When we increased the stoichiometric amount of $\mathrm{H}_{2} \mathrm{O}_{2}$ to $100 \%$, the SEM images showed a film of Ag polyhedral NPs (Fig. 3C) with EDS spectra corresponding to pure Ag (Fig. 3C, squares 1 and 2). TEM images show the typical product - polyhedral Ag NPs (Fig. 3D).

\section{Reaction mechanism}

The phase and composition analysis of the reaction intermediates shows the formation of a silver(I) oxide $\mathrm{Ag}_{2} \mathrm{O}$ crystalline phase. $\mathrm{Ag}_{2} \mathrm{O}$ is the best-known oxide of silver, which is usually produced from the anodic oxidation of $\mathrm{Ag}$; it is amphoteric and can be reduced by hydrogen peroxide $\left(\mathrm{H}_{2} \mathrm{O}_{2}\right.$, a redox compound that is also amphoteric) to yield $\mathrm{Ag} .{ }^{22}$ The $\mathrm{Ag}_{2} \mathrm{O}$ solid phase mediates the formation of silver in a particle-mediated mechanism. The $\mathrm{Ag}_{2} \mathrm{O}$ particles are reduced by $\mathrm{H}_{2} \mathrm{O}_{2}$, and the TEM analysis of a sub-stoichiometric reaction (Fig. 3B) shows the formation of a biphasic $\mathrm{Ag}_{2} \mathrm{O} / \mathrm{Ag}$ Janus particle as an intermediate.

The reaction follows a surface driven mechanism where $\mathrm{H}_{2} \mathrm{O}_{2}$ chemisorbs and reacts on the surface of $\mathrm{Ag}_{2} \mathrm{O}$ particles followed by reduction and growth of the pure $\mathrm{Ag}$ phase, like a reaction with a reducing gas. ${ }^{23}$ On a broader view, the reaction proceeds through the following three stages:

$\mathrm{Ag}^{+}$reaction with PVP (complexation + slight reduction)

$$
2 \mathrm{Ag}_{(\mathrm{aq})}{ }^{+}+2 \mathrm{OH}_{(\mathrm{aq})}{ }^{-} \rightarrow \mathrm{Ag}_{2} \mathrm{O}_{(\mathrm{s})}+\mathrm{H}_{2} \mathrm{O}_{(\mathrm{l})}
$$

$\mathrm{Ag}_{2} \mathrm{O}_{(\mathrm{s})}+\mathrm{H}_{2} \mathrm{O}_{2(\mathrm{aq})} \rightarrow 2 \mathrm{Ag}_{(\mathrm{s})}+\mathrm{H}_{2} \mathrm{O}_{(\mathrm{l})}+\mathrm{O}_{2(\mathrm{~g})}$ (formally but with a large excess of $\mathrm{H}_{2} \mathrm{O}_{2}$ )

The third step of the mechanism is coined in the scheme in Fig. 3E. After formation of $\mathrm{Ag}_{2} \mathrm{O}_{(\mathrm{s})}$ which forms the large particle observed by SEM, hydrogen peroxide $\mathrm{H}_{2} \mathrm{O}_{2}$ reduces the $\mathrm{Ag}_{2} \mathrm{O}$ on their surface, as demonstrated by the presence of binary biphasic $\mathrm{Ag}_{2} \mathrm{O} / \mathrm{Ag}$ Janus particle. The reaction continues until completion of the reduction process to yield pure Ag NPs.

The mediated-particle mechanism described above presents a significant departure from the mainstream mechanism, which involves the formation of an intermediate phase of $\mathrm{AgCl}^{24-27}$ or $\mathrm{AgBr}^{28}$ The most popular reaction involves the formation of $\mathrm{AgCl}$, which rapidly precipitates and stays in equilibrium with $\mathrm{Ag}^{+}$ions that are further reduced to $\mathrm{Ag}$. This mechanism allows to control the shape of the nanocrystals, especially for the formation of $\mathrm{Ag}$ nanowires. ${ }^{29}$ In the case of $\mathrm{Ag}_{2} \mathrm{O}$ formation, this competitive mechanism is very unlikely, and the TEM provides evidence only for a surface driven mechanism.

The two mechanisms, halogenide- or oxide-based, involve markedly different kinetics of reaction. As the intermediate phase $\mathrm{Ag}_{2} \mathrm{O}$ reacts directly with $\mathrm{H}_{2} \mathrm{O}_{2}$ to form the $\mathrm{Ag}$ nanocrystals, the reaction is much faster than in the case of $\mathrm{AgCl}\left(K_{\mathrm{sp}}\right.$ $\left.=1.8 \times 10^{-10}\right)$ or $\operatorname{AgBr}\left(K_{\mathrm{sp}}=5.0 \times 10^{-13}\right)$ intermediates where only a very low concentration of $\mathrm{Ag}^{+}$ions is available for the nanocrystal growth. The slow kinetics allows an excellent shape control with relatively long reaction time even on small batches. Such a sluggish reaction can impede the industrial production of Ag inks. On the contrary, the mechanism described here is compatible with a scale-up, and batches of 100-1000 g of Ag nanocrystals were produced on a routine basis.

\section{Application to printed electronics}

The polyhedral Ag NPs display a high purity and volume fraction with a very low content of stabilizer (PVP). When formulated as an ink (60\% wt in tripropylene glycol methyl ether (TPM)), the NPs can be easily coated on a glass to form silver lines with a dispenser (Fig. 4 inset and experimental part). The four-probe resistivity of the pristine lines $(1600 \mu \Omega \mathrm{cm})$ is about 1000 times greater than the bulk $\mathrm{Ag}$ resistivity $(1.59 \mu \Omega \mathrm{cm}$, Fig. 4). A gentle annealing under air at $200{ }^{\circ} \mathrm{C}$ for 15 minutes brought the resistivity down to $15 \mu \Omega \mathrm{cm}$ (9.4 times the bulk value). A further annealing for 45 minutes brought the resistivity down to $10.5 \mu \Omega \mathrm{cm}, 6.6$-fold greater than the bulk resistivity. These results are remarkable and fit the needs of conductive inks in printed electronics. The very low annealing temperature is compatible with polymer substrate and packaging.

The high conductivity of the Ag lines reveals the high density of the Ag NPs assembly. SEM images of the lines (pristine and annealed) show the dense packing of polyhedral NPs (Fig. 5).

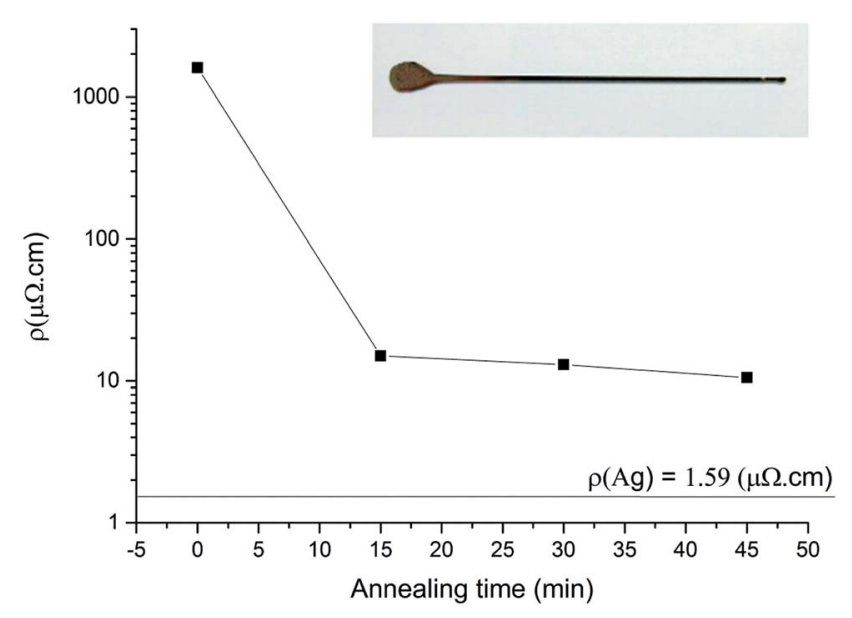

Fig. 4 Resistivity vs. annealing time curves while heating at $200{ }^{\circ} \mathrm{C}$. Photograph of the Ag line (inset). 


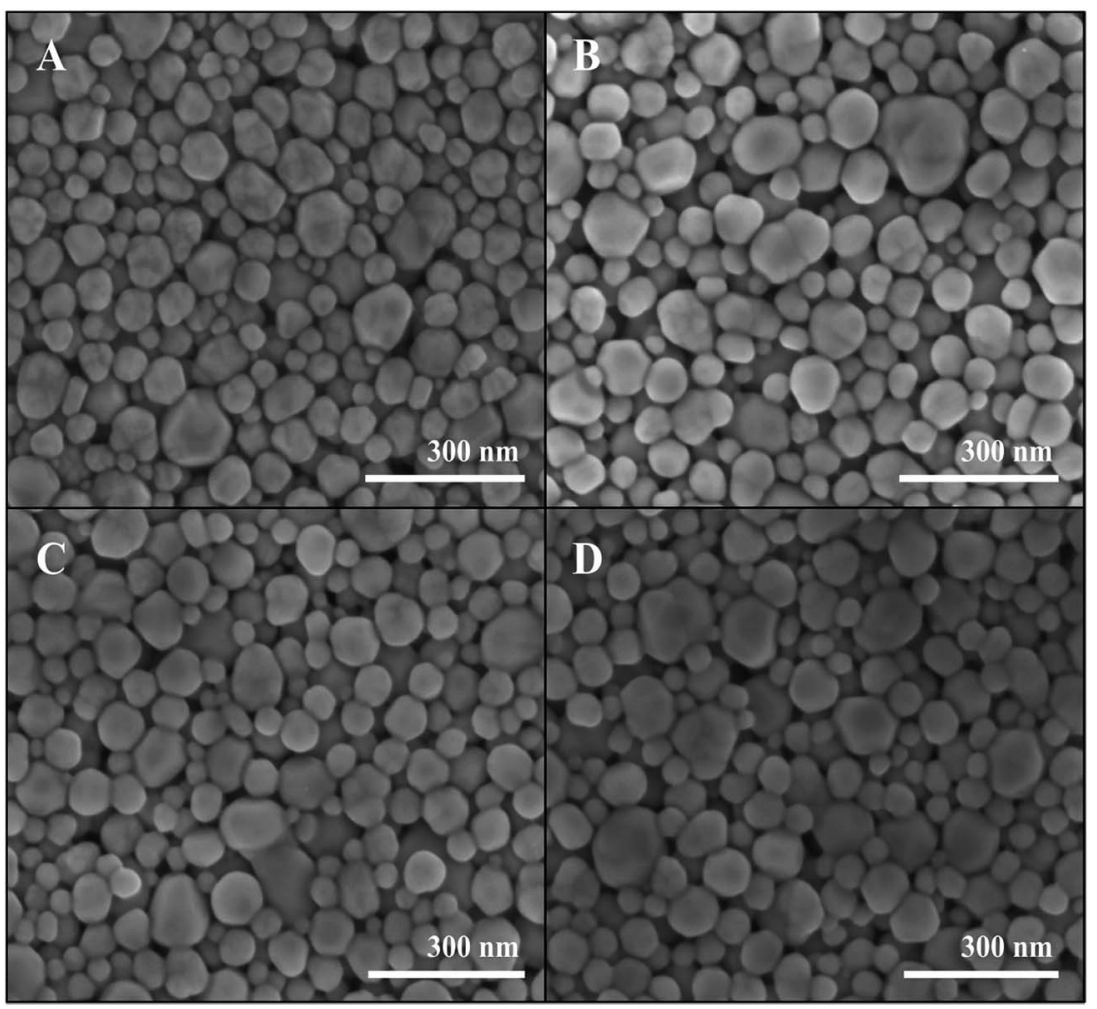

Fig. 5 HRSEM micrographs of Ag lines at different annealing time (A) $0 \mathrm{~min}$, (B) $15 \mathrm{~min}$, (C) $30 \mathrm{~min}$ and (D) $45 \mathrm{~min}$.

The HRSEM shows no detectable change during the annealing process, hence the annealing does not lead to any coarsening or shape evolution of the NPs. Nevertheless, the resistivity decreases by two orders of magnitude during the annealing. This spectacular enhancement does not result from any change in size $(64 \pm 20 \mathrm{~nm})$, density, shape, or grain boundaries, and therefore results from the interface between the polyhedral $\mathrm{Ag}$ NPs. Such a mechanism underlines the high importance of the shape of the Ag NPs. Indeed, an extensive interface between the particles is only achieved with polyhedral NPs and not with spherical ones.

\section{Conclusions}

The large-scale synthesis of polyhedral Ag nanoparticles (NPs) described here follows a mediated-particle mechanism through the formation of rectangular-shaped $\mathrm{Ag}_{2} \mathrm{O}$ microcrystals. The reaction proceeds through a surface driven conversion of $\mathrm{Ag}_{2} \mathrm{O}$ to Ag. The PVP-stabilized silver NPs display a low polydispersity in size and shape distribution with a large majority of faceted NPs. The rapid and simple reaction described here is compatible with a scale-up, and batches of 100-1000 g of Ag nanocrystals were routinely and consistently produced. The formulation of polyhedral silver NPs in high volume fraction ink easily forms conductive lines. The resistivity reaches 6.6 times the bulk resistivity after a gentle annealing at $200{ }^{\circ} \mathrm{C}$. Finally, this original synthesis pathway is fully compatible with a largescale production in the field of printed electronics on soft substrates such as polymers.

\section{Experimental}

\section{Chemicals}

$\mathrm{AgNO}_{3} \quad(63.5 \% \mathrm{Ag}$, Holland Moran), polyvinylpyrrolidone powder (PVP, $M_{\mathrm{W}}=55000$, Sigma-Aldrich), KOH (90\%, ChenSamuel, Israel), and $\mathrm{H}_{2} \mathrm{O}_{2}$ as $35 \%$ water solution (Makhteshim, Israel) were used without further purification. Antifoaming agent Contraspum 1012 was obtained from Zschimmer \& Schwarz, Germany. Aqueous solutions were prepared using deionized (DI) water (Ionex purification system, PuriTech, Belgium).

\section{Synthesis of Ag nanocrystals}

$52.5 \mathrm{~g}$ of $\mathrm{AgNO}_{3}$ and $35 \mathrm{~g}$ of PVP were dissolved in $600 \mathrm{ml}$ of DI water (solution 1). Five drops of anti-foaming agent were added into solution 1, and $19 \mathrm{~g}$ of $\mathrm{KOH}$ were dissolved in $100 \mathrm{ml}$ of water (solution 2). Solution 2 was poured into solution 1 under intensive stirring, forming a colloidal precipitate of $\mathrm{Ag}_{2} \mathrm{O}$. Then, $180 \mathrm{ml}$ of $\mathrm{H}_{2} \mathrm{O}_{2}$ were added at $\sim 10 \mathrm{ml} \mathrm{min}^{-1}$ under intensive stirring directly into the reaction mixture, to reduce the silver oxide to silver. During the addition of $\mathrm{H}_{2} \mathrm{O}_{2}$, the exothermic reaction resulted in a temperature increase from $25{ }^{\circ} \mathrm{C}$ to $60-$ $65{ }^{\circ} \mathrm{C}$. The reaction mixture was stirred for an additional 10 minutes and then transferred to a membrane separation system for purification (ceramic hollow fiber cross-flow membrane, $100 \mathrm{~nm}$ pore size). The resulting water dispersion was concentrated to $\sim 60 \mathrm{~g}$ solution contained about $30 \mathrm{~g}$ of Ag nanocrystals ( $\sim 90 \%$ yield based on $\mathrm{AgNO}_{3}$ ). 


\section{Batches for elucidating the reaction mechanism}

(A) Partial reduction ( $\sim 10 \%$ "quenching") of $\mathrm{Ag}_{2} \mathrm{O}$ into $\mathrm{Ag}$. A colloidal precipitate of $\mathrm{Ag}_{2} \mathrm{O}$ was formed as described above, and $20 \mathrm{ml}$ of $\mathrm{H}_{2} \mathrm{O}_{2}-$ about $10 \%$ of the stoichiometric amount needed for full reduction - were added over $\sim 2$ min to the reaction mixture under intensive stirring. The reaction mixture was then stirred for an additional 10 minutes, and the obtained dispersion was purified and washed.

(B) Semi-reduction ( $\sim 50 \%$ "quenching") of $\mathrm{Ag}_{2} \mathrm{O}$ into $\mathrm{Ag}$. To the colloidal precipitate of $\mathrm{Ag}_{2} \mathrm{O}$ formed as described above, $90 \mathrm{ml}$ of $\mathrm{H}_{2} \mathrm{O}_{2}-$ about $50 \%$ of the stoichiometric amount needed for full reduction - were added at $\sim 10 \mathrm{ml} \mathrm{min}^{-1}$ into the reaction mixture under intensive stirring. The reaction mixture was then stirred for an additional 10 minutes, and the resultant dispersion was purified and washed.

\section{Characterization}

The structure of the NPs was investigated using transmission electron microscopy (TEM): JEOL 1400 at $120 \mathrm{kV}$. High resolution scanning electron microscopy (HRSEM) images were collected on a FEI Magellan equipped with an energy-dispersive X-ray (Oxford $80 \mathrm{~mm}^{2}$ ) spectroscopy (EDS) attachment. EDS was typically collected on images with an area of $25 \mu \mathrm{m}^{2}$ to provide a statistical analysis on different regions and a reliable composition. The crystalline phases and crystallinity of the prepared powders of intermediate and final products were examined by XRD using $\mathrm{Cu} \mathrm{K} \alpha(0.1541 \mathrm{~nm})$ radiation (Bruker Advance D8).

Printing of the conductive line was achieved with an air pressure dispenser on a custom CNC equipped with a heated stage between $60-80{ }^{\circ} \mathrm{C}$ with a jog velocity of 500-1000 $\mathrm{mm} \min ^{-1}$ and pressure between $0.7-2.5$ psi.

\section{Conflicts of interest}

There are no conflicts to declare.

\section{References}

1 X. Xia, J. Zeng, Q. Zhang, C. H. Moran and Y. Xia, J. Phys. Chem. C, 2012, 116, 21647-21656.

2 T. Zhang, Y. J. Song, X. Y. Zhang and J. Y. Wu, Sensors, 2014, 14, 5860-5889.

3 Y. Wang, D. Wan, S. Xie, X. Xia, C. Z. Huang and Y. Xia, ACS Nano, 2013, 7, 4586-4594.

4 M. Cortie, Chem. Rev., 2011, 111, 3713-3735.
5 J. Perelaer, P. J. Smith, D. Mager, D. Soltman, S. K. Volkman, V. Subramanian, J. G. Korvink and U. S. Schubert, J. Mater. Chem., 2010, 20, 8446.

6 Z. Zhang, X. Zhang, Z. Xin, M. Deng, Y. Wen and Y. Song, Nanotechnology, 2011, 22, 425601.

7 Y. Sun, Chem. Soc. Rev., 2013, 42, 2497-2511.

8 R. Ma, C. Levard, S. M. Marinakos, Y. Cheng, J. Liu, F. M. Michel, G. E. Brown and G. V. Lowry, Environ. Sci. Technol., 2012, 46, 752-759.

9 Q. Zhang, N. Li, J. Goebl, Z. Lu and Y. Yin, J. Am. Chem. Soc., 2011, 133, 18931-18939.

10 Y. Qin, X. Ji, J. Jing, H. Liu, H. Wu and W. Yang, Colloids Surf., A, 2010, 372, 172-176.

11 Y. Cao, R. Zheng, X. Ji, H. Liu, R. Xie and W. Yang, Langmuir, 2014, 30, 3876-3882.

12 B. Wiley, T. Herricks, Y. Sun and Y. Xia, Nano Lett., 2004, 4, 1733-1739.

13 D. Chen and L. Gao, J. Cryst. Growth, 2004, 264, 216-222.

14 Y. Xia, X. Xia, Y. Wang and S. Xie, MRS Bull., 2013, 38, 335344.

15 Y. Wang, Y. Zheng, C. Z. Huang and Y. Xia, J. Am. Chem. Soc., 2013, 135, 1941-1951.

16 B. J. Murray, Q. Li, J. T. Newberg, E. J. Menke, J. C. Hemminger and R. M. Penner, Nano Lett., 2005, 5, 2319-2324.

17 G. Wang, X. Ma, B. Huang, H. Cheng, Z. Wang, J. Zhan, X. Qin, X. Zhang and Y. Dai, J. Mater. Chem., 2012, 22, 21189.

18 J. Jo, S. P. Cho and J. K. Lim, J. Colloid Interface Sci., 2015, 448, 208-214.

19 Z. Yang, L. Zhang, H. You, Z. Li and J. Fang, Part. Part. Syst. Charact., 2014, 31, 390-397.

20 P. Yang, Y. Zhang and B. Huang, Mater. Res. Bull., 2013, 48, 3756-3760.

21 J. Fang, S. Liu and Z. Li, Biomaterials, 2011, 32, 4877-4884.

22 S. Klosky and L. Woo, J. Phys. Chem., 1926, 30, 1930-1931.

23 G. Schimo, A. M. Kreuzer and A. W. Hassel, Phys. Status Solidi A, 2015, 212, 1202-1209.

24 Y. Xia, Y. Xiong, B. Lim and S. E. Skrabalak, Angew. Chem., Int. Ed., 2009, 48, 60-103.

25 W. M. Schuette and W. E. Buhro, ACS Nano, 2013, 7, 38443853.

26 R. Long, S. Zhou, B. J. Wiley and Y. Xiong, Chem. Soc. Rev., 2014, 43, 6288.

27 Y. Zheng, J. Zeng, A. Ruditskiy, M. Liu and Y. Xia, Chem. Mater., 2014, 26, 22-33.

28 F. Wu, W. Wang, Z. Xu and F. Li, Sci. Rep., 2015, 5, 10772.

29 R. Gottesman, A. Tangy, I. Oussadon and D. Zitoun, New J. Chem., 2012, 36, 2456. 